\title{
Decreasing the Effect of Ultra Violet Ray on Polypropylene by Using Chromium Tri-oxide
}

\author{
Zainab Fadhil Kadhim \\ Metallurgy Department, College of Materials Engineering, Babylon University, Babylon, Iraq
}

Email address:

bbabel24@gmail.com

To cite this article:

Zainab Fadhil Kadhim. Decreasing the Effect of Ultra Violet Ray on Polypropylene by Using Chromium Tri-Oxide. International Journal of Materials Science and Applications. Vol. 5, No. 2, 2016, pp. 95-101. doi: 10.11648/j.ijmsa.20160502.20

Received: April 5, 2016; Accepted: April 19, 2016; Published: May 7, 2016

\begin{abstract}
Chromium tri-oxide $\left(\mathrm{CrO}_{3}\right)$ / polypropylene sheets have been prepared by twin screw extruder machine. Polypropylene (PP) is being used in producing tanks, pressure vessels, and other outer doors applications to reduce original cost. The effect of ultraviolet ray has been studied because of the tertiary carbon bonds in PP chain structure is the center of UV attack. Mechanical tests (tension, flexural, hardness, and creep) have been carried out on $\left(\mathrm{CrO}_{3} / \mathrm{PP}\right)$ with proportions $(0.05 \%, 0.1 \%)$. The results show that, after different intervals of UV exposure $\left(\mathrm{CrO}_{3}\right)$ works as stabilizer and plasticizer at the same time.
\end{abstract}

Keywords: Thermoplastic, Polypropylene (PP), Ultraviolet (UV), Chromium Tri-oxide $\left(\mathrm{CrO}_{3}\right)$, Degradation

\section{Introduction}

Thermoplastic polymers are repeatedly softened to offer desired shape on heating with some precautions (the temperature of heating on specified pressure should be well below the decomposition temperature of the polymers). These polymers are transferred into dimensionally hard materials after cooling without any change in their properties thus they remain soluble and fusible even after formation of article in their final stages. [1]

Many polymers that used in consumer products were degraded by UV light, and need addition of UV absorbers to inhibit attack, especially if the products were exposed to sunlight. The problem appears as discoloration or fading, cracking, and, sometimes, total product disintegration if cracking has proceeded sufficiently. The rate of attack increases with exposure time and sunlight intensity. [2]

Long term exposure to sunlight leads to the degradation of plastic materials. In particular, the non-visible UV radiation characterized by short wavelengths is responsible for photodegradation, a process that generally results in breaking down the polymer chains. This frequently results in a deterioration of the physical properties, changes in color or chalking of the part surface. UV radiation represents only $4.6 \%$ of the solar spectrum, but causes the most important damage to the polymeric materials. In order to limit or postpone the onset of degradation, several types of UV light stabilizers can be added to the polymer. $[3,17]$

The complete solar UV spectrum ranges between 280 and 400 nanometers, but the most aggressive part is the UVB range with very short wavelengths between 280 and 315 nanometers. In order to limit or postpone the onset of degradation, several types of UV light stabilizers can be added to the polymer. The most important stabilizer types work by screening out the harmful ultraviolet light - for instance UV absorbers such as benzophenones or small dispersed particles such as carbon black or inorganic pigments. $[3,4]$

Polypropylene is one of thermo plastic polymers. It is a lightweight heat-resistant, semi-rigid material ideally suited for use in applications at elevated temperature. In steam applications low moisture absorption rate and resistance to staining makes it an excellent choice. High tensile strength coupled with impact resistance and high compressive strength allow it to be used in a multitude of structural applications. [5, 19]

Polypropylene also demonstrates excellent chemical resistance, good abrasion resistance, good dimensional stability, and a high surface gloss on finished pieces. The versatility of this polymer makes it particularly well suited for film and fibers requiring superior strength, optical qualities, grease resistance, and moisture barrier properties. [6] 
Polypropylene has also been the material choice to replace tanks and other vessels fabricated from specialty metals such as stainless steel because of reduced original cost and long term cost savings benefits over the life of the equipment. [7]

Transition metal oxide has many applications as catalyst in conversion processes of hydrocarbons, sensors, superconductors and adsorbents. Metal-oxides constitute an important class of materials that are involved in environmental science, electrochemistry, biology, chemical sensors, magnetism and other fields. Chromium oxides have attracted much attention recently because of their importance both in science and technology. As the chromium has different stable oxidation states, it can form the different types of oxides. [8]

Many crystalline modifications of $\mathrm{Cr}$ oxide exist, such as $\mathrm{Cr}_{2} \mathrm{O}_{3}$ (corundum), $\mathrm{CrO}_{2}$ (rutile), $\mathrm{Cr}_{5} \mathrm{O}_{12}$ (three-dimensional framework), $\mathrm{Cr}_{2} \mathrm{O}_{5}$ and $\mathrm{CrO}_{3}$ (unconnected strings of $\mathrm{CrO}_{4}$ tetrahedra) [9]. $\mathrm{CrO}_{3}$ is an important compound for automobile industries due to its high corrosion resistance properties. In these industries, $\mathrm{CrO}_{3}$ is used for plating the chromium on car body and other auto components. Chromium trioxide shows a very high electron affinity, which indicates that it should be a strong oxidizing agent which enables it to be used in various pharmaceutical and chemical industries [10]. It is also reported that $\mathrm{CrO}_{3}$ complexes exhibit the antibacterial activity against Pseudomonas aeruginosa bacteria. In crystal structure of $\mathrm{CrO}_{3}$, its molecules form the chains of $\mathrm{CrO}_{4}$ tetrahedra, which are linked at corner oxygen. [11]

\section{Literature Review}

Barbara Lipp and others (2006) studied the effect of UV radiation on polyamide and polypropylene fibers, which are characterized by various macroscopic features, colors and additives. They conclude that UV radiation under the exposure conditions used brings about changes in both the fiber structure and mechanical properties. Polypropylene fibres, commonly regarded as the most degradable under the influence of UV radiation, maintain a high stability of their structure owing to the incorporation of UV stabilizers; this is reflected in the relatively small change in their mechanical properties. Titanium dioxide in an appropriately high concentration (matt fibre) has a clear protective effect on the polymer. [12]

Y. Amintowlieh and others (2012) modify melt strength or decreasing molecular weight distribution of polypropylene by using photointiator. benzophenone (BPH) is used as photoinitiator for generating the radicals in the PP backbone. UV radiation is conducted in solid state. Effect of radiation duration on the degree of degradation and long chain branching (LCB) are studied in this work. They concluded more irradiation time results in higher viscosities and more shear thinning behavior. [13]

Marlene Lawston (2015) studied Different types of polymers have unique structures making some polymers more susceptible to UV attack and others more UV-stable. By using Fourier Transform Infrared Spectroscopy to compare five different polymer samples, polyethylene (with adhesive) was determined to be the least UV-stable while Polyimide was determined to be the most UV-stable. Further research to be conducted should include testing the UVstability of multiple types of polyimides and more stages of UV-Ozone exposure. [14]

\section{Experimental Part}

\subsection{Equipment}

1. Twin Screw extrusion machine of polymer: Model SLJ$30 \mathrm{~A}$, screw diameter $30 \mathrm{~mm}$, heating power $3 \mathrm{kw}$, main motor $4 \mathrm{kw}$, speed is $(0-320) \mathrm{rpm}$.

2. Saw Electrical Device (Einhell RT-SB305U).

3. Grinding Electricity Device (Bench Grinder BG611)

4. UV Radiation Device: Xenon lamp intensity $2.3 \mathrm{w} / \mathrm{m}^{2}$, wave length (300-350) $\mathrm{nm}$.

5. Microcomputer Controlled Electronic Universal Testing Machine: Model WDW-5E, tensile and flexural fixtures; D638, D790 for tensile and flexural specimens.

6. Hardness Device (Shore D TH210).

7. Creep testing machine: WP600 Kriech tester Herstell-Nr.

\subsection{Sample Preparation}

Sample preparation process including three stages:

First: PP granular $(100 \mathrm{~g})$ has been extruded through fine orifices of the twin screw extruder machine at $190^{\circ} \mathrm{C}$ and cooled by air without any addition, PP granulars (100g) has been extruded with flakes of chromium tri-oxide with two proportions $\left(0.05 \% \mathrm{CrO}_{3}, 0.1 \% \mathrm{CrO}_{3}\right)$.

Second: after extrusion process, each polymer sheet (pure $\mathrm{PP}, \mathrm{PP} / 0.05 \%, \mathrm{PP} / 0.1 \%$ ) has been cut into samples of (tensile, flexural, creep and hardness tests) by using saw electrical device.

Third: before the mechanical tests, grinding has been carried out for each sample by applying grinding machine.

Number of samples are 36: 9 for each test (tensile, flexural, creep, hardness), each of these tests has been carried out on 9 samples as following: pure $\mathrm{PP}, \mathrm{PP} / 0.05 \% \mathrm{CrO}_{3}$, $\mathrm{PP} / 0.1 \% \mathrm{CrO}_{3}$, PP $(25,75)$ hours, $\mathrm{PP} / 0.05 \%(25,75)$ hours, $\mathrm{PP} / 0.1 \%(25,75)$ hours. Creep test has been carried out in the same procedure with the exception of the period of UV exposure that is equal to $(19,28)$ hours.

\section{Results and Discussions}

\subsection{Tensile Property}

PP has maximum tensile strength where maximum load $(0.9 \mathrm{KN})$ against maximum deformation $(8 \mathrm{~mm})$, through the addition of chromium tri-oxide $(0.05 \%)$, the tensile strength was decreased into maximum load $(0.85 \mathrm{KN})$ and maximum deformation (4 mm), with increasing the amount of chromium tri-oxide into $(0.1 \%)$ the maximum load was decreased into $(0.45 \mathrm{KN})$ while deformation was increased to max. value $(14 \mathrm{~mm})$ because of the ceramic oxide $\left(\mathrm{CrO}_{3}\right)$ works as plasticizer increasing the deformation more than 
other samples (Fig. 1).

$(\mathrm{PP} / 0.1 \%)$ sample has max. tensile strength after $25 \mathrm{hrs}$ of UV exposure whereas max. load $(0.92 \mathrm{KN})$ \& $\max$. deformation $(4 \mathrm{~mm})$ followed by the $(\mathrm{PP} / 0.05 \%)$ where $\max$. load $(0.7 \mathrm{KN}) \&$ max. deformation $(3 \mathrm{~mm})$ while $(\mathrm{PP})$ sample has min. tensile strength, $(0.63 \mathrm{KN}) \&$ min. deformation $(2.8$ $\mathrm{mm}$ ) as in (Fig. 2). PP have no carbonyl or $\mathrm{C}=\mathrm{C}$ bonds within their regular structure, the chromophoric moieties are introduced into the backbone or side groups through the high temperature injection moulding and extrusion processes. Initiation of the photochemical degradation reactions can occur via free radical mechanisms, leading to the formation of hydroperoxides and chain scission [17] but chromium VI oxide enhanced the properties of PP with UV exposure because chromium tri-oxide prevent deterioration of the polymer due to environmental [15] as a stabilizer.

After $75 \mathrm{hrs}$ of UV exposure the two samples (PP, PP/0.05) have max. tensile strength where max. load $(0.35 \mathrm{KN})$ corresponded to min. deformation $(1 \mathrm{~mm})$ while the $(\mathrm{PP} / 0.1 \%)$ sample has min. load $(0.075 \mathrm{KN})$ corresponded to max. deformation ( $9 \mathrm{~mm}$ ) as in (Fig. 3). From previous figure the curves of (PP \& PP/0.05)) analogues the behavior of glass which is called glassy polymer while the curve of (PP/0.1) behaves as rubber which is called rubbery polymer. [16]

\subsection{Flexural Property}

Max. flexural strength is observed by PP sample where max. load $(0.12 \mathrm{KN})$ and max. deformation $(7 \mathrm{~mm})$; min. flexural strength is observed by $(\mathrm{PP} / 0.05 \%)$ sample whereas max. load $(0.05 \mathrm{KN})$ and max. deformation $(9 \mathrm{~mm})$ while the sample $(\mathrm{PP} / 0.1)$ is showed intermediate values (Fig. 4). This means that $\mathrm{CrO}_{3}$ works on plasticizing the polymer in spite of its ceramic nature and $(\mathrm{PP} / 0.1 \%)$ gives best properties than $(\mathrm{PP} / 0.05)$.

After $25 \mathrm{UV}$ exposure the sample (PP/0.05\%) has max. flexural strength where max. load and deformation are $(0.14$ $\mathrm{KN}$ and $7 \mathrm{~mm}$ ) while the samples (PP, PP/0.01) have max. load $(0.1 \mathrm{KN})$ and max. deformations are $(5 \mathrm{~mm} \& 7 \mathrm{~mm})$ respectively. The sample of $(\mathrm{PP} / 0.05 \%)$ is showed improvement in the flexural strength after ( 25 hours) from UV exposure (Fig. 5). Due to the effect of UV radiation on the performance of polymers, the rate of photodegradation of polymeric materials is often retarded by the use of UV stabilisers [17].

Max. flexural strength can be observed after $75 \mathrm{hrs}$ of UV exposure through the specimen (PP/0.05\%) where max. load and deformation are $(0.1 \mathrm{KN} \& 7 \mathrm{~mm})$ and for the specimen (PP/0.1\%) max. load and deformation are $(0.08 \mathrm{KN} \& 7 \mathrm{~mm})$ while the specimen (PP) has $(0.06 \mathrm{KN}$ and $5 \mathrm{~mm})$ as in Fig. (6). In spite of decreasing flexural strength for three specimens after $75 \mathrm{hrs}$ of UV exposure but the specimen $\left(\mathrm{PP} / 0.05 \% \mathrm{CrO}_{3}\right)$ is the best in flexural strength.

\subsection{Creep Property}

Samples (PP, PP/0.05) have instantaneous elastic deformation $(1 \mathrm{~mm})$ and the extension increasing with time where max. extension of PP is $(3.4 \mathrm{~mm})$ and max. extension of $(\mathrm{PP} / 0.05 \%)$ is $(3 \mathrm{~mm})$ while $\left(\mathrm{PP} / 0.1 \% \mathrm{CrO}_{3}\right)$ sample has instantaneous elastic deformation $(1.4 \mathrm{~mm})$ and max. extension is $(2.4 \mathrm{~mm})$. It can be observed that the creep rate (extension against time) is decreased with time because of the chromium tri-oxide while the instantaneous elastic deformation of $(\mathrm{PP} / 0.1 \%)$ is more than (PP, $\mathrm{PP} / 0.05 \%$ ) as in (Fig. 7).

For (PP/0.05\%) sample, max. elastic deformation and max. extension with time are $(1.5 \mathrm{~mm}, 2.8 \mathrm{~mm})$ respectively after $18 \mathrm{hrs}$ of UV exposure, and for (PP) max. elastic deformation and max. time dependent extension are $(1.3 \mathrm{~mm}, 2.4 \mathrm{~mm})$ while (PP/0.1) has max. elastic and time dependent extension $(1.2 \mathrm{~mm}, 2 \mathrm{~mm})$ respectively (Fig. 8). The specimen (PP/0.05\%) after (19 hours) from exposure to UV ray show max. extension and this means that $\left(\mathrm{CrO}_{3}\right)$ works as stabilizer and plasticizer at the same time.

After $28 \mathrm{hrs}$ of UV exposure (PP) sample has max. elastic deformation and max. time dependent extension $(2 \mathrm{~mm}$, $2.9 \mathrm{~mm}$ ) respectively while the samples (PP/0.05\%, $\mathrm{PP} / 0.1 \%$ ) have max. elastic deformations and time dependent extension (1.6mm, $1.4 \mathrm{~mm}, 2.3 \mathrm{~mm}$ ) respectively (Fig. 9).

\subsection{Hardness Property}

PP sample is showed increasing in hardness from (59.1 to 73.01) with the effect of radiation which make the polymer is more brittle [18]. The hardness of $(\mathrm{PP} / 0.05 \%)$ sample is (63.2) (more than PP alone) and this returns to the ceramic stabilizer $\left(\mathrm{CrO}_{3}\right)$ that has high hardness, after $(25 \mathrm{hrs})$ hardness is decreased to (57.53) and this returns to the effect of $\mathrm{CrO}_{3}$ as stabilizer and plasticizer; then hardness is increased into (59.73) under the effect of $75 \mathrm{hrs}$ of UV exposure. The hardness of (PP/0.1\%) sample is (69.7) because the amount of chromium tri-oxide $\left(\mathrm{CrO}_{3}\right)$ is more than the previous specimens because this oxide is behaved as a stabilizer to protect polymers in outer door against the high energy ultraviolet radiation from the sun and occasionally indoors when exposed to fluorescent lights [19]. After $25 \mathrm{hrs,}$ the hardness decreases to (65.73) and after (75 hours) the hardness is decreased into (64.77) as (Fig. 10).

\section{Conclusions}

From this work we can summaries the following conclusions:

1. From tensile test, the proportion $\left(0.1 \%\right.$ of $\left.\mathrm{CrO}_{3}\right)$ as stabilizer against UV was the best after 25 hours of radiation.

2. $0.05 \%$ of $\mathrm{CrO}_{3}$ as stabilizer against UV degradation was the best proportion after $(25 \& 75)$ hrs of UV exposure through flexural test.

3. The creep rate has been decreased due to the effect of $\mathrm{UV}$ ray and $\mathrm{CrO}_{3}$ as a stabilizer.

4. The hardness has been increased with time of UV exposure while for $(\mathrm{PP} / 0.05 \%, \mathrm{PP} / 0.1 \%)$ the hardness has been decreased after UV exposure due to the effect of $\mathrm{CrO}_{3}$.

5. For all tests $\mathrm{CrO}_{3}$ works as stabilizer and plasticizer at the same time. 


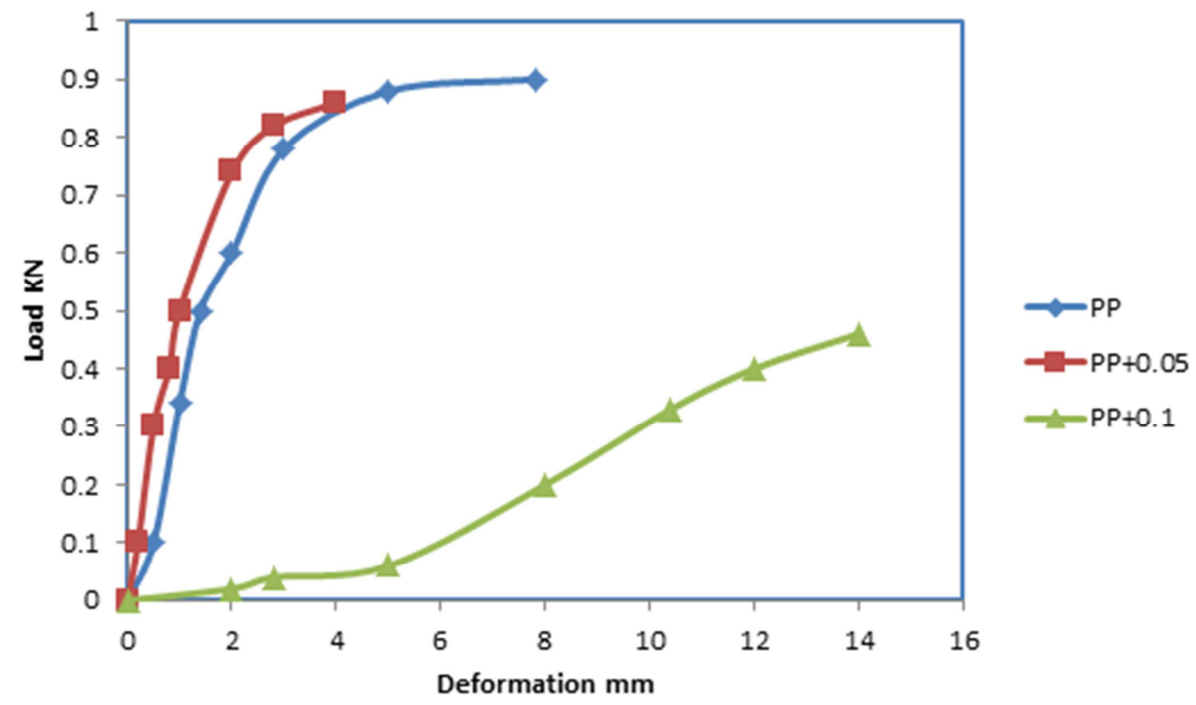

Figure 1. Tensile strength curves of $\left(\mathrm{PP}, \mathrm{PP}+0.05 \% \mathrm{CrO}_{3}, \mathrm{PP}+0.1 \% \mathrm{CrO}_{3}\right)$ samples.

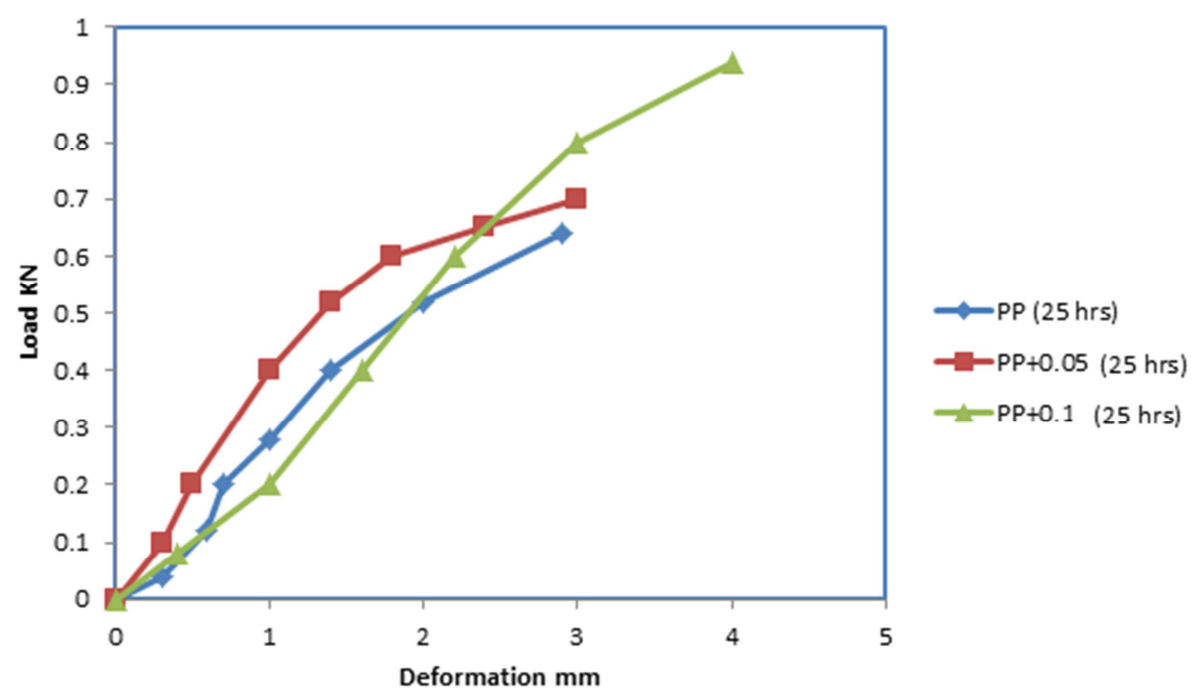

Figure 2. Tensile strength curves of ( $\left.P P, P P+0.05 \% \mathrm{CrO}_{3}, \mathrm{PP}+0.1 \% \mathrm{CrO}_{3}\right)$ samples after (25 hours) from UV exposure.

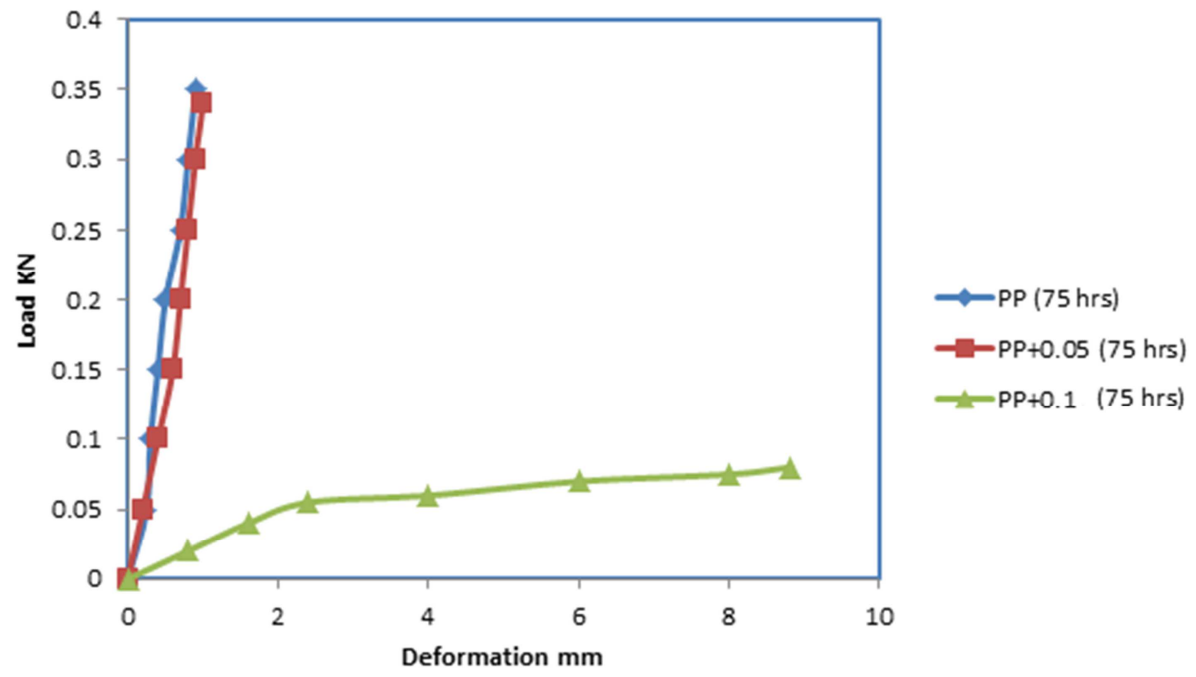

Figure 3. Tensile strength curves of ( $\left.P P, P P+0.05 \% \mathrm{CrO}_{3}, \mathrm{PP}+0.1 \% \mathrm{CrO}_{3}\right)$ samples after (75 hours) from UV exposure. 


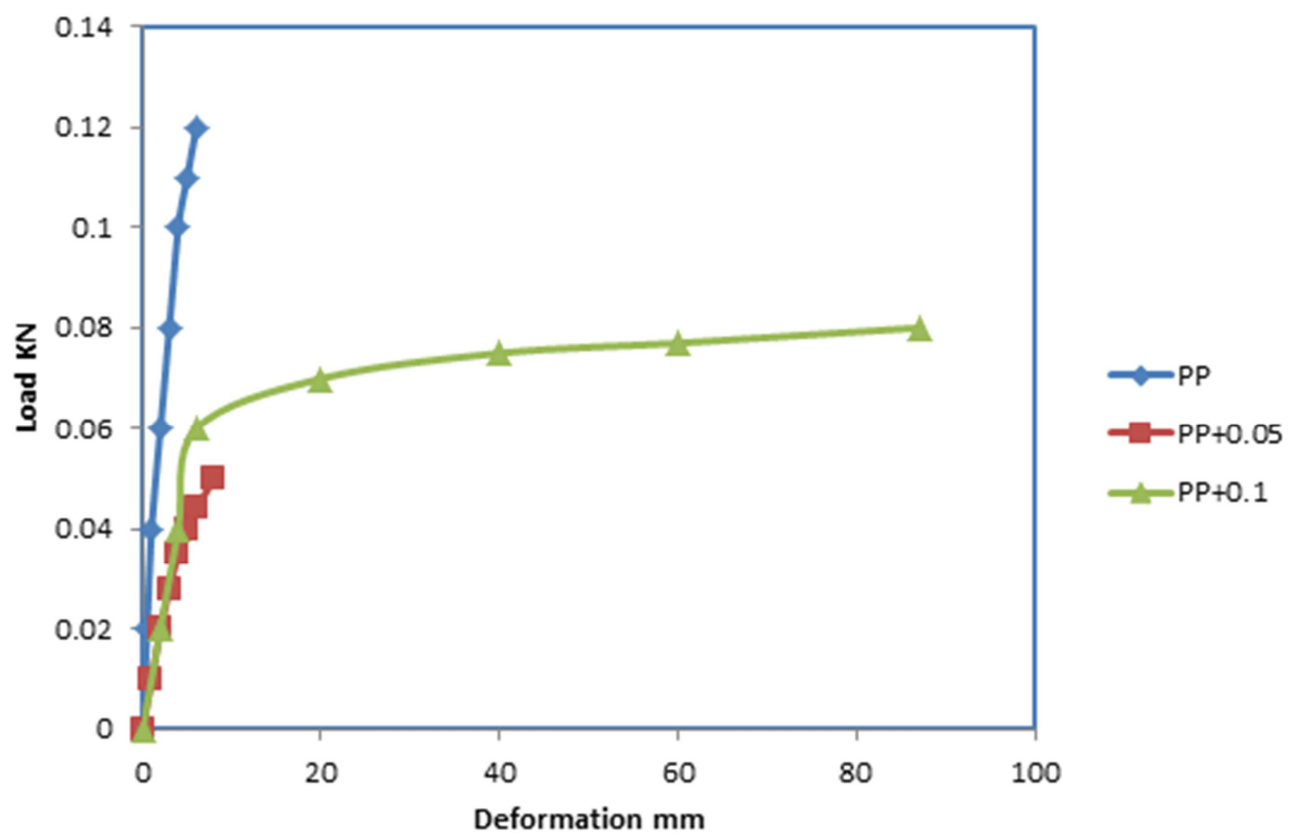

Figure 4. Flexural strength curves of $\left(\mathrm{PP}, \mathrm{PP}+0.05 \% \mathrm{CrO}_{3}, \mathrm{PP}+0.1 \% \mathrm{CrO}_{3}\right)$ samples.

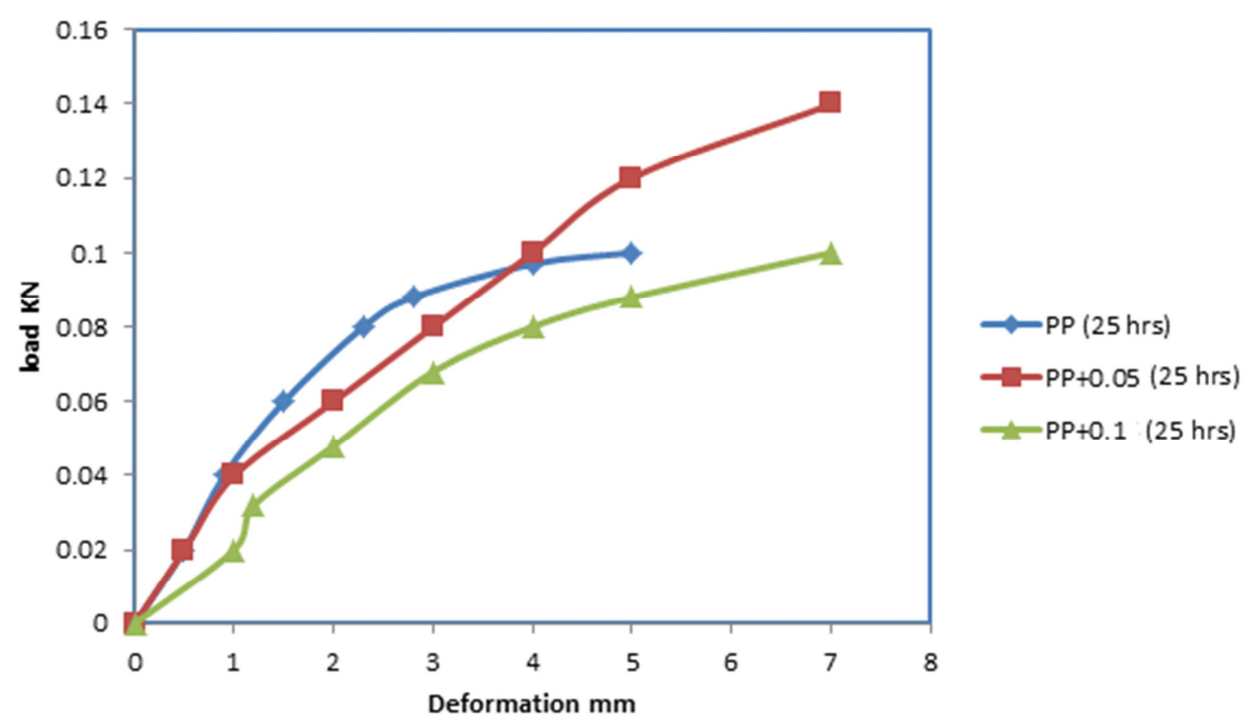

Figure 5. Flexural strength curves of $\left(\mathrm{PP}, \mathrm{PP}+0.05 \% \mathrm{CrO}_{3}, \mathrm{PP}+0.1 \% \mathrm{CrO}_{3}\right)$ samples after (25 hours) from UV exposure.

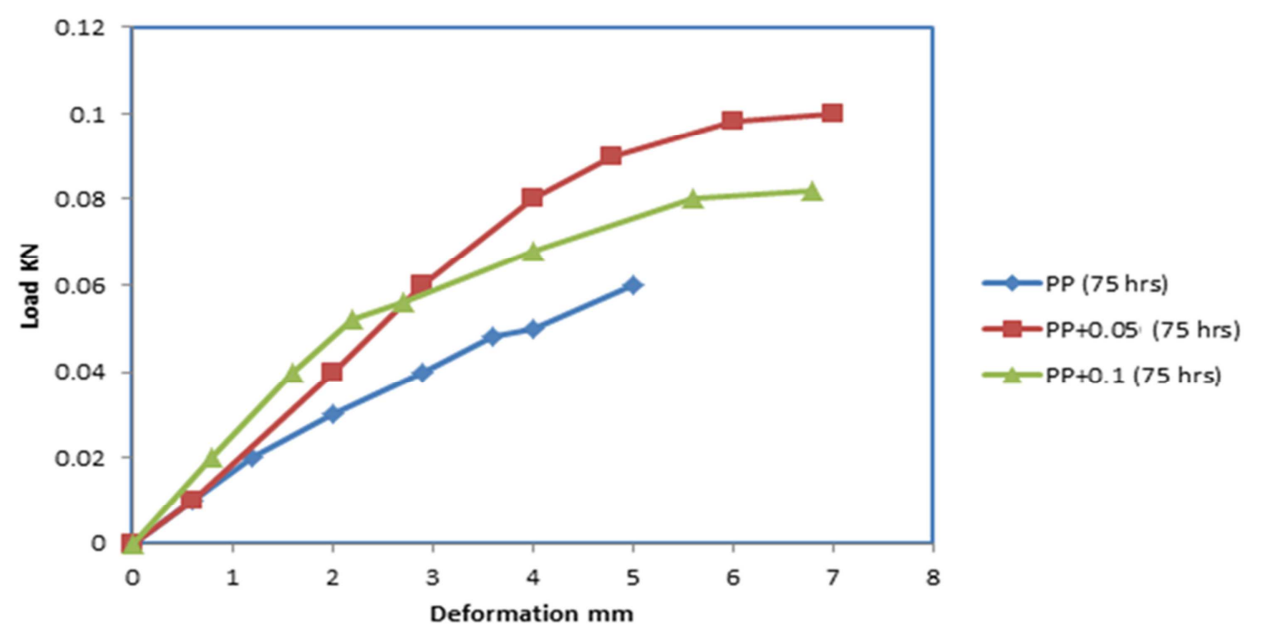

Figure 6. Flexural strength of $\left(\mathrm{PP}, \mathrm{PP}+0.05 \% \mathrm{CrO}_{3}, \mathrm{PP}+0.1 \% \mathrm{CrO}_{3}\right)$ samples after (75 hours) from UV exposure. 


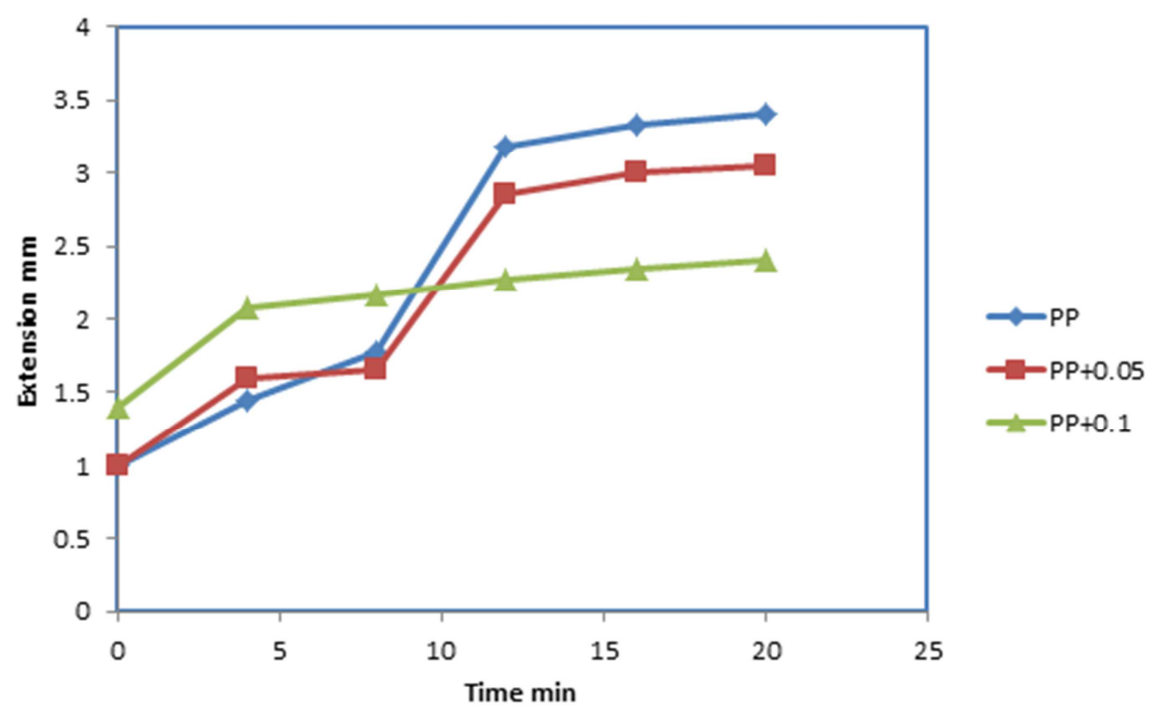

Figure 7. Creep curves of $\left(\mathrm{PP}, \mathrm{PP}+0.05 \% \mathrm{CrO}_{3}, \mathrm{PP}+0.1 \% \mathrm{CrO}_{3}\right)$ samples.

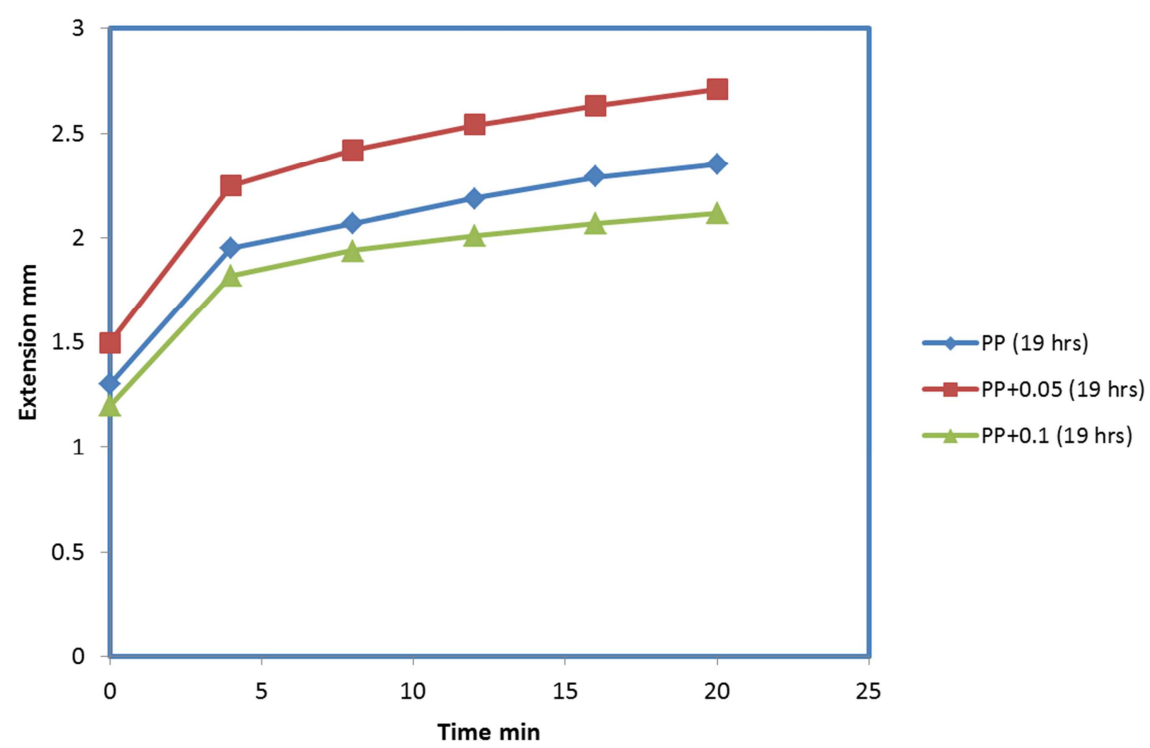

Figure 8. Creep curves of ( $\mathrm{PP}, \mathrm{PP}+0.05 \% \mathrm{CrO}_{3}, \mathrm{PP}+0.1 \% \mathrm{CrO} \mathrm{O}_{3}$ ) samples after (19 hours) from UV exposure.

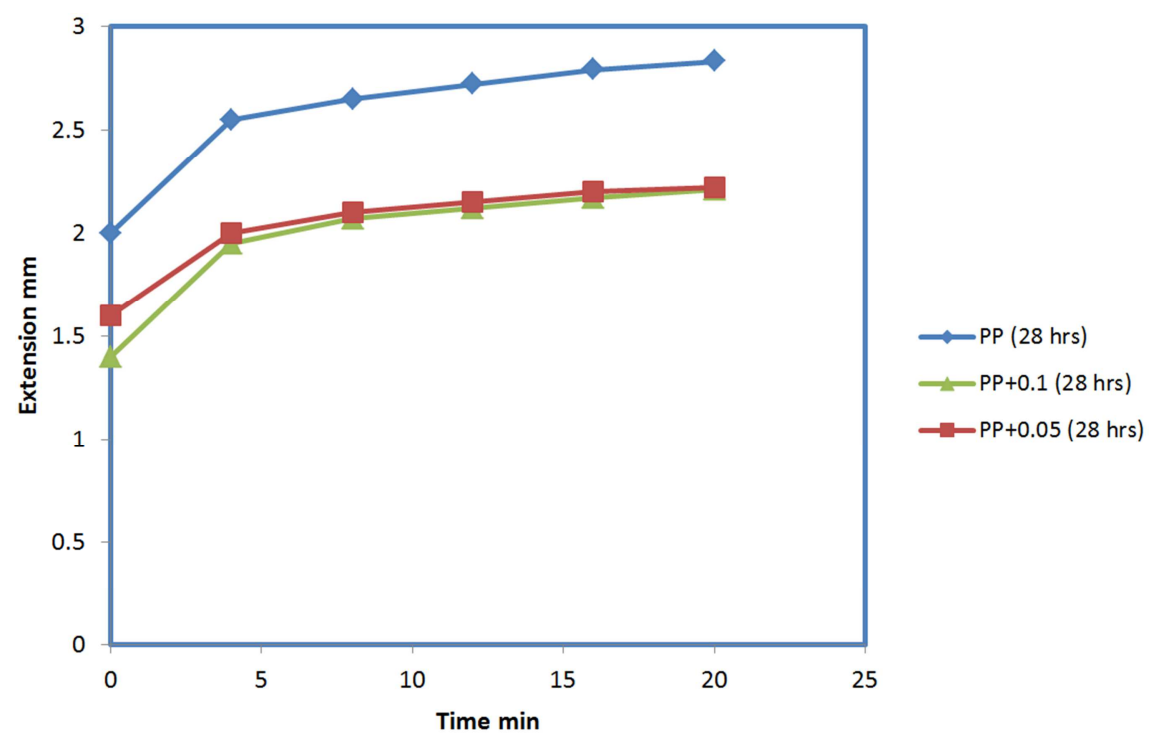

Figure 9. Creep curves of $\left(\mathrm{PP}, \mathrm{PP}+0.05 \% \mathrm{CrO}_{3}, \mathrm{PP}+0.1 \% \mathrm{CrO}_{3}\right)$ samples after (28 hours) from UV exposure. 


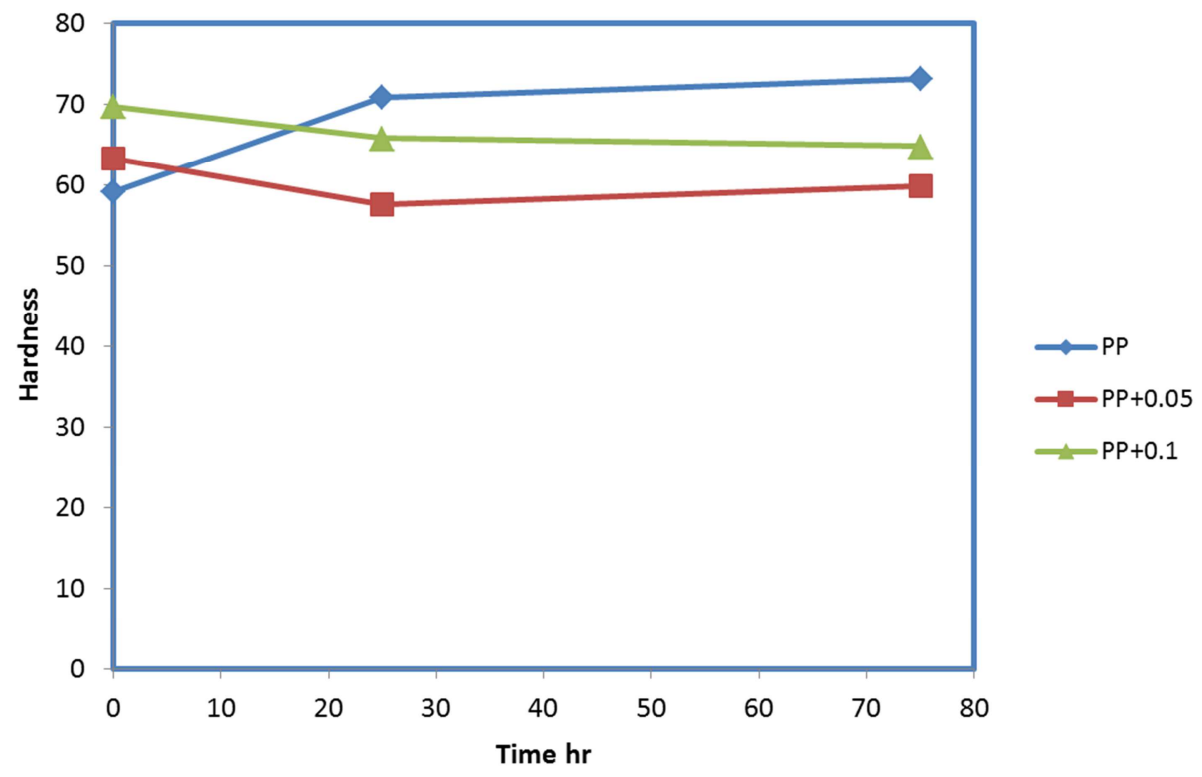

Figure 10. Hardness values of $\left(\mathrm{PP}, \mathrm{PP}+0.05 \% \mathrm{CrO}_{3}, \mathrm{PP}+0.1 \% \mathrm{CrO} \mathrm{O}_{3}\right)$ versus different times of $U V$ exposure.

\section{References}

[1] Karak Niranjan, (2009), "Fundamentals of polymers Raw Materials to Finish Products", PHI Learning Private Limited, New Delhi.

[2] Massy Liesl K., (2007), "The Effects of UV Light and Weather on Plastic and Elastomers", Second Edition, United State of America, Willam Andrew, Inc.

[3] CAPOT, "UV Weathering and Related Test Methods", www.cabot-corp.com/plastics.

[4] U. S. Global Change Research Information Office, "UV Damage to Polymers", Pennsylvania, NW, Washington, http://www.gcrio.org/.

[5] E. Jorden Brookes, "engineered metals and plastics", www.EJBCO.com.

[6] INEOS, (2007), "Polypropylene Processing Guide", Olefins and polymers USA, www.ineos-op.com.

[7] Alcock Benjamin (2004), "Single Polymer Composites Based on Polypropylene: Processing and Properties", the PhD thesis, University of London, Queen Mary, Materials Department, UK.

[8] Ritu, (2015), "Synthesis and Characterization of Chromium Oxide Nanoparticles", IOSR Journal of Applied Chemistry, Vol. 8, Issue 3.

[9] Ivanova T, Gesheva K, Cziraki A, Szekeres A and Vlaikova E, (2008),"Structural transformations and their relation to the optoelectronic properties of chromium oxide thin films", Journal of Physics, series 113.

[10] Gutsev G. L., Jena P., Zhai Hua-Jin and Wang Lai-Sheng, (2001) "Electronic structure of chromium oxides, $\mathrm{CrO}_{\mathrm{n}}^{-}$and CrOn $(n=1-5)$ from photoelectron spectroscopy and density functional theory calculations", Journal of chemical physics, Vol. 115, No. 17.
[11] Trivedi Mahendra Kumar, Tallapragada Rama Mohan, Branton Alice, Trivedi Dahryn, Nayak Gopal, Latiyal Omprakash, and Snehasis Jana, (2015), "Characterization of Physical, Thermal and Structural Properties of Chromium (VI) Oxide Powder: Impact of Biofield Treatment", powder metallurgy and mininig, Vol. 4. Issue 1.

[12] Symonowicz Barbara-Lipp, Sztajnowski Sławomir, Kardas Iwona, (2006), "Influence of UV Radiation on The Mechanical Properties of Polyamide and Polypropylene Fibers in Aspect of Their Restructuring", Autex Research Journal, Vol. 6, No. 4.

[13] Amintowlieh. Y. and others (2012), "Modification of Polypropylene by UV-Radiation", University of Waterloo, N2L 3G1 Canada.

[14] Lawston Marlene, (2015), "The Effect of Ultraviolet and Ultraviolet - Ozone Exposure on Polymers", Niskayuna High School.

[15] Askeland Donald R., (1991), "THE Science and Engineering of Materials", university of Missouri-rolla, Great Britain by Clays Ltd, St Ives, ISBN 041234260.

[16] McCrum N. G., Buckley C. P., Bucknall C. B, (1997), "Principles of Polymer Engineering", Oxford university Press Inc., NewYork, Great Britain by Bookcraft Ltd., Midsomer Norton, Avon, ISBN 0198565275.

[17] Callaghan, S. J. (2001), "Comparing Weathering of Plastics", BUILD, BRANZ. Wellington.

[18] Singh Bhupendra Butola, (2013), "Photostability of HDPE Filaments Stabilized with UV Absorber UVA and light stabilizer HALS", Journal of Engineering Fibers and Fabrics, vol. 8 , issue 1 .

[19] harper A. Charles., (2006), "Handbook of Plastics Technologies", United States OF America, McGraw-Hill, ISBN 0-07-146068-3. 